\title{
MAINFRAME TO ENTERPRISE TO THE IS CURRICULUM
}

\author{
Joseph Packy Laverty, Robert Morris University, Laverty@rmu.edu \\ Frederick G. Kohun, Robert Morris University, kohun@rmu.edu \\ John Turchek, Robert Morris University, turchek@rmu.edu \\ David Wood, Robert Morris University, wood@rmu.edu \\ Daniel Rota, Robert Morris University, rota@rmu.edu
}

\begin{abstract}
Over the decades the concept of a mainframe has been synonymous to IBM operating systems and the COBOL programming language. While object-orientated programming languages, web interface transaction systems, web services, distributed services, and mobile application topics are frequently included in the IS/CS curriculum, this paper considers the inclusion of IBM Enterprise Systems. IBM zEnterprise has evolved into an integrated, scalable, enterprise system which supports legacy applications, open-source applications and tools, DB2, Cognos, SPSS, data mining and Rational project management tools. The growth and market penetration of IBM zEnterprise has been spectacular. This evolution of IBM Enterprise Systems provides many opportunities for IS/CS majors. A case study implementing the IBM Academic Initiative in an ABET-CAC curriculum is presented.
\end{abstract}

KEYWORDS: IBM Academic Initiative, IS Curriculum, IBM zEnterprise, ABET-CAC, z/OS, COBOL, CICS, DB2, Open Source, Rational Application Developer for Z Systems, Robert Morris University, Marist College

\section{INTRODUCTION}

Over the decades the concept of a mainframe has been synonymous to IBM operating systems and the COBOL programming language [1]. In recent years, computer hardware evolved in various directions, e.g., desktop, blade servers, super computers and mobile devices. Operating systems, at the same time, evolved into high availability, distributed, virtualized, and cloud-based architectures. Applications have embraced a variety of processing modes, user interfaces, object-orientation, mobile platforms and open source tools. IBM zEnterprise has evolved into an integrated, scalable enterprise system which supports legacy applications, open-source applications and tools, DB2, Cognos, SPSS, data mining and Rational project management tools. The growth and market penetration of IBM zEnterprise has been spectacular.

The evolution of hardware, operating systems, and applications has changed the focus from a Mainframe to an Enterprise architecture. The organization and content of many IS curricula reflect this evolution. Yet, research has shown that the IS curriculum rarely includes zEnterprise technologies An informal review of 47 ABET-CAC accredited schools found that 11 institutions still list at least one course in the COBOL programming language in their published web site catalogs. Most COBOL offerings were not based on IBM z/OS. Three institutions offered other courses covering zEnteiprise topics. The frequency of theses course offerings were unable to be determined by this informal review [2]. The conclusion from this informal review indicated that university support IBM zEnterprise within the IS/CS/IT curriculum was very limited. However, all universities reviewed offered a course in either the JAVA or VB.NET application programming languages, and coverage of a Microsoft or Linux operating system.

IBM Enterprise Systems have quietly increased their dominance of large-scale transaction processing, virtual and cloud-based infrastructures. It is estimated that there are over 120,000 large-scale, IBM transaction processing data centers located in the United States [26]. This paper focuses on the following issues 1) Evolution of IBM Enterprise Systems, 2) Opportunities for IS/CS majors in IBM Enterprise Systems, and 3) A Case Study implementing the IBM's Academic Initiative. 


\section{Issues in Information Systems}

Volume 13, Issue 2, pp. 182-192, 2012

\section{EVOLUTION TO IBM ENTERPRISE SYSTEMS}

While proud of their history of reliability, availability, serviceability, extensibility, and scalability [4, p 9-29], IBM has become synonymous with Mainframe Technology -"the big-box in the back room." Today, IBM prefers that customers and educators use a more appropriate title that reflects the current status of IBM technologies, i.e., IBM Enterprise Systems, or zEnterprise.

From a hardware perspective, the IBM zEnterprise has extended its big-box approach to support blade servers, SANs, LPARs, clusters, and cloud services. zEnterprise's replacement for the OS/390 operating system was named $\mathrm{z} / \mathrm{OS}$. The evolution to a 64-bit architecture was significant in terms of memory management and throughput. zEnterprise added support for enterprise computing, open source operating systems and application programming languages, while continuing support for traditional mainframe systems, programming languages and standards, e.g., TSO, JSE, CICS, IMS, DB2, and RACF. z/OS system administration now includes various web-based and clientbased tools to supplement traditional JCL, REXX, ISPF, and TSO system administration facilities. Additionally, z/OS can communicate using TCP/IP and supports traditional internet services, such as the Apache Web Server, Websphere Application Server (J2EE), FTP, NFS, and CIFS.

\section{IBM Virtualization, Operating Systems and Hypervisors}

While VMware may be the most popular microprocessor virtualization solution, it is not the most dominant or widely used. IBM actually pioneered the use of virtualized operating systems in 1972. z/VM is the current name of a family of IBM virtualized operating systems. There is a need to distinguish between IBM LPAR (logical partitions) and z/VM. LPARs are based on hardware partitioning boundaries built into the firmware and interpartition communication [6,7]. An LPAR is a subset of the processor and memory that is designed to support an operating system. For example, a mainframe may be configured with two LPARS, each having a separate copy of zOS. One logical partition (LPAR) may run single copy of the z/OS operating system with appropriate resources to support production operations. A second logical partition (LPAR) containing a second z/OS operating system may support development or testing. LPARs only support one copy of an operating system.

LPARs enable processors, memory, and I/O devices to be dynamically allocated and shared between LPAR regions at the hardware level. LPAR architectures running the z/OS or zLinux operating system can dynamically share multiple processors within one mainframe (Sysplex) or multiple processors between distributed mainframes (Parallel Sysplex). x86 virtualization solutions are limited to local and assigned remote processors and must be rebooted when the hardware configuration has been changed [8,9]. Therefore, LPARs are a more effective solution to handling changes in system load, such as a temporary peak load. LPARs can dynamically reallocate hardware resources, while virtual machines (software-based) cannot. It should be noted that HP and Sun also provide LPAR hardware solutions [10].

A hypervisor, or virtual machine manager, is software that permits multiple operating systems to run concurrently on a host computer. Type-1 hypervisors permit a guest operating system to communicate directly with the hardware. Type-2 hypervisors do not directly communicate with the hardware and use a second distinct layer of software between the host operating system and guest operating system. All hypervisors are software based; whereas, LPARs are built into the firmware and does not require an extra layer of software. zVM, VMware, XEN, and xSphere are examples of Type- 1 hypervisors. LPARs simply run faster, have more features, and are more scalable, secure and reliable.

IBM's LPAR architecture supports only z/OS, z/VM, and zLinux. z/OS is a full featured operating system, while $\mathrm{z} / \mathrm{VM}$ is a hypervisor. One limitation of LPARs is the difficulty of maintaining a large number of guest operating systems. A Type-1 hypervisor, like z/VM, provides more flexibility in implementing and managing up to 24,576 virtual machines (guest operating systems), provides dynamic I/O configuration, and Parallel Access Volume (PAV) support [18]. z/VM is a more appropriate solution to automatically manage large-scale distributed server consolidations. z/VM can support a large number of z/TPF, z/OS, zLinux and zNSE guest operating systems. While 


\section{Issues in Information Systems}

Volume 13, Issue 2, pp. 182-192, 2012

z/VM cannot support Windows directly, z/VM will support a zLinux virtual machine and VMware. VMware can support any Windows- based operating systems $[9,10]$. See Figure 1.

Figure 1

IBM LPARs, z/VM Virtualization and Guest Operating Systems

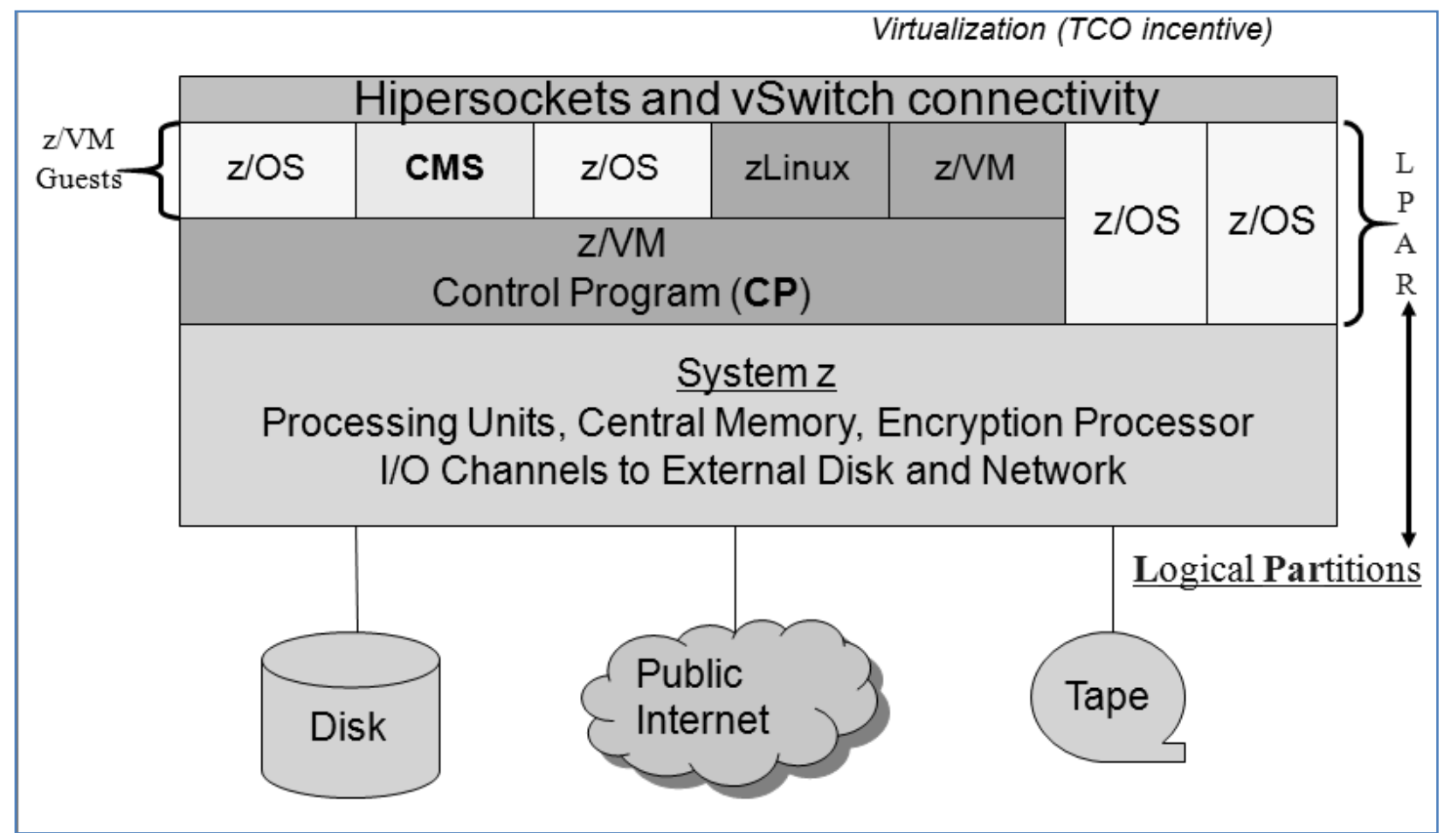

J2EE Application Development, WebSphere, Rational and Cognos

Many organizations may start with Microsoft or Linux/Unix solutions. As long as large-scale processing requirements and scalability are not a major concerns, the cost, ease of development and administration of these solutions may be advantageous. On the other hand, there is a need to consider those organizations that may already have a legacy investment in IBM mainframe technologies, requirements for high transaction processing volume, or the need to consolidate large number of servers. Today's IBM Enterprise Systems can easily integrate web, mobile and web services within the existing IBM legacy architecture while leveraging scale and the investment in existing applications, business and technical expertise. IBM data center consolidations have proven to reduce operating costs, licensing and vendor support costs by $40 \%$ or more, while also doubling performance.

Eclipse, an open source IDE, has been a popular application development tool for the Java application. IBM's Rational Application Developer (RAD) extends the Eclipse J2EE IDE to IBM Enterprise technologies. WebSphere core servers provide an application infrastructure that supports J2EE web applications, SOA, and portals. Rational Application Developer for zEnterprise (rDz) extends the Eclipse IDE to COBOL, C/C++, CICS, IMS, DB2, and other mainframe applications. Both Rational IDEs are integrated into the IBM Rational Project Management and Testing suite. Additionally, IBM Cognos integrates back-end data warehouses integrate a wide variety of business intelligence, data mining, and performance tools. All zEnterprise systems support TCP/IP, a web and transaction server, SSH and FTP. 


\section{Issues in Information Systems}

Volume 13, Issue 2, pp. 182-192, 2012

\section{OPPORTUNITIES FOR IS/CS MAJORS IN IBM ENTERPRISE SYSTEMS}

\section{IBM Enterprise Systems Dominates Large-scale Transaction Processing}

In response to changing industry needs, new technologies have been integrated into the IS/CS curriculum. Application programming languages, such as Java, C\#, NET and VB.NET, are common requirements in the IS/CS curriculum. Unix, Linux or Windows desktop or servers operating systems are important IS/CS operating system topics. Microsoft Access, SQL Server and Oracle database management systems, as well as, J2EE and ASP.NET application frameworks are popular IS/CS enterprise-level courses And currently, mobile application development is the "hot" new technology within the IS/CS curriculum.

Certainly, the IS \& CS curricula cannot ignore the growing demand for mobile application programmers. However, mobile applications and web interfaces are only a part of a complete enterprise system solution - the user interface. PNC's Virtual Wallet [19] represents a typical web and mobile application for the retail banking industry. After a mobile remote request has been submitted, a high volume application or transaction server must receive and process the web or mobile transaction. While web and mobile interfaces may be new, the business logic of most retail banking transactions have not changed for decades. Enterprise designers frequently access existing legacy applications through web services, remote calls, or transaction servers. Existing legacy databases, data warehouses, and reporting applications remain key components of web and mobile enterprise systems. While, web and mobile interfaces are new, the large-scale processing infrastructure behind these new technologies are not.

PNC, like so many other large corporations, has built their existing enterprise systems on IBM Enterprise technologies. For example, behind this mobile application there may be an IBM WebSphere Application Server or CICS transaction server, a COBOL application, and a IMS or DB2 database. Each component executes using IBM hardware infrastructure and IBM's z/OS or Linux operating systems. Besides leveraging the investment in IBM legacy technologies, IBM Enterprise Systems are frequently the only alternative that offers level of scalability that is necessary to support large scale transaction volume to security, availability and reliability requirements. The growth of large-scale web and mobile transaction applications has also expanded the demand for IBM Enterprise Systems. However, IS/CS curricula may have focused only on the 'tip of the iceberg", the user interface. As the user may be unaware of the "'big box" behind the web or mobile app, it is important to consider whether the IS/CS curriculum is also may be unaware of zEnterprise opportunities for curriculum and students.

While there is no surprise that IBM dominates the mainframe market with over a 90\% market share in 2011 [13], Gartner also reports that IBM and HP are fighting for the number one position in the enterprise server market with $35 \%$ market share $[15,16]$. From a hardware perspective IBM dominates high-end servera, data center consolidation, cluster and cloud services marketplace. In April of 2012, Gartner reported that IBM was the leading software vendor with a worldwide sales volume of $\$ 19.2$ billion dollars spent for application infrastructure and middleware software [12]. Specifically IBM held the number one position is areas such as application development, transaction processing, business process management, and portal software. Double-digit growth in IBM business analytics, security, mobile and cloud software were also reported. IBM Enterprise Systems also dominate many industries, e.g., all of the top 25 world banks, $71 \%$ of global Fortune 500 companies, and nine out of the top ten global life/health insurance providers process their high-volume transactions on an IBM Enterprise System [12]. More than 50\% of major U.S. retailers, airlines and manufacturers rely of IBM Enterprise systems. And the I.R.S., F.B.I, Department of Defense, other government agencies and major defense contractors are heavily committed to IBM zEnterprise technologies.

\section{Future Shortages of Qualified zEnterprise Entry-Level Candidates}

The lack of inclusion of IBM zEnterprise topics in the IS/CS curriculum may be explained. The high operational cost and administration of IBM mainframes, previous lack of support of IBM for academic institutions, and the low visibility and attractiveness of IBM careers may be possible causes. On the other hand, the reduce cost, simpler 


\section{Issues in Information Systems}

Volume 13, Issue 2, pp. 182-192, 2012

infrastructure management, easy application development, academic support, may have served to expand the role of Intel and Apple desktop and server systems within the IS/CS curriculum. As a result, the decrease inclusion of zEnterprise topics in the IS/CS curriculum, coupled with the increased demand for IBM zEnterpise job candidates may have created a shortage of academically-prepared IBM zEnterpise students.

Interviews with eleven major IBM zEnterprise employers have indicated concerns of the age distribution of zEnterprise system engineers and application developers. There was common agreement that by 2020, there will be a critical shortage of IBM zEnterprise qualified employees. While it was difficult to get comprehensive and accurate estimate of projected retirements and the potential growth of zEnterprise systems, some estimates predict forty to fifty thousand IBM zEnterprise positions will become available over the next decade. The increased demand for domestic and global IBM zEnterprise expertise and an aging workforce means opportunities for IS \& CS graduates.

\section{Case Background}

\section{IBM ACADEMIC INITIATIVE CASE STUDY}

The history of the Robert Morris University's (RMU) Computer Information Systems (CIS) program may provide insight into how other ABET-CAC accredited information systems programs may respond zEnterprise infrastructure, operating systems, and applications. In 1997, the RMU-CIS RMU department regularly offered four courses in IBM technologies. These courses were Introduction to COBOL, Advanced COBOL, COBOL Application Programming using CICS, and COBOL Application Programming using DB2. The core operating system course also included significant coverage of the IBM OS/360 topics and an introduction to JCL. However, the CIS department did not have access to an IBM mainframe. This curriculum was based on MicroFocus COBOL and various third-party CICS and DB2 add-on products. As web-based systems and microcomputer server technologies matured, student and employer interest in IBM mainframe technologies waned. By 2000, courses and topics related IBM technologies were no longer offered.

\section{IBM Academic Initiative}

IBM has supported Academic Initiatives for faculty, researchers and students for many years. Details and registration information may be found on the IBM Academic Initiative web site [20]. After an academic institution has been registered, faculty and students are eligible to receive hundreds of IBM software products and technologies at no cost. In order to participate, both faculty and students must individually register for the IBM academic initiative. Faculty and students are required to list an IBM approved academic institution. Universities and faculty can access physical or virtual mainframe systems, courseware, and training at no cost. Students can access to online texts, PDFs, online training, podcasts, videos, enterprise contests, certification exam discounts, zEnterprise resume posting database and jobs portal [27]. While students do not have access to IBM Academic Initiative courseware, other valuable education resources are available to the student.

Table 1 provides an overview of IBM Academic Initiative Courseware topics available to instructors. More than 400 universities worldwide are enrolled in IBM's Academic Initiative for System z. Many Academic Initiative universities have developed and made available courseware for System z, Rational, Business Intelligence, WebSphere, Java and other topics Approximately 17,000 members, world-wide, use the Academic Initiative each year [14]. Some IBM courseware includes Power Point presentations, PDF course books, hands-on assignments, sample tests, instructor guide, syllabi and other instructional materials. Other courseware may be delivered via online tutorials. IBM Academic Initiative courseware is rated as introductory, intermediate, or advanced. 


\section{Issues in Information Systems \\ Volume 13, Issue 2, pp. 182-192, 2012}

Table 1

A Selection IBM Academic Initiative Courseware and PDF Text Books

\begin{tabular}{|l|}
\hline \multicolumn{1}{|c|}{ Category/Link } \\
\hline System Z and Legacy \\
https://www14.software.ibm.com/web \\
app/devtool/scholar/web/coursewareP \\
ickPage.do?source=ai-course-systemz \\
\\
Information Management \\
https://www14.software.ibm.com/web \\
app/devtool/scholar/web/coursewareP \\
ickPage.do?source=ai-course-dim
\end{tabular}

Security

https://wwwl4.software.ibm.com/web app/devtool/scholar/web/coursewareP ickPage.do?source=ai-course-security Rational

https://wwwl4.software.ibm.com/weba $\mathrm{pp} /$ devtool/scholar/web/coursewarePic

kPage.do?source=ai-course-rsdd

\section{Project Management} kPage.do?source=ai-course-pm Category/Link ( continued)

Information Infrastructure https://wwwl4.software.ibm.com/weba pp/devtool/scholar/web/coursewarePic kPage.do?source=ai-course-infoinfra

\section{Cloud Computing}

https://wwwl4.software.ibm.com/weba kPage.do?source=ai-course-cloud https://wwwl4.software.ibm.com/weba pp/devtool/scholar/web/coursewarePic $\mathrm{pp} /$ devtool/scholar/web/coursewarePic

\author{
Selection of Course Topics \\ Introduction to Mainframes, z/OS Basics and Advanced, z/VM and Virtualization, \\ Networking, ISPF, PCOMM \\ COBOL, VSAM, CICS, IMS, DB2, JCL, Mainframe Security, Assembler, \\ WebSphere Web Application Server and zLinux, RAS \\ "Introduction to the New Mainframe: z/OS Basics" PDF Text Book \\ http://publib.boulder.ibm.com/Redbooks.nsf/RedbookAbstracts/sg246366.htmi \\ "Introduction to the New Mainframe: Networking" PDF Text Book \\ http://publibb.boulder.ibm.com/Redbooks.nsf/RedbookAbstracts/sg246772.htmi \\ "Introduction to the New Mainframe: Security" PDF Textbook \\ http://www.redbooks.ibm.com/abstracts/sg246776.htmi \\ Rational System Architect and Enterprise Architecture Concepts, e.g., SWOT \\ tables, workflow diagrams, data models, use cases, system diagrams, network \\ diagrams, project plans, etc. \\ Rational Focal Point - web-based Requirements Management and Project Portfolio Mgt. \\ Business Modeling and Business Process Analysis \\ Rational DOORS - requirements management \\ Rational Rhapsody- collaborative design and development for systems engineers \\ and software developers creating real-time or embedded systems and software. \\ Rational Synergy - distributed and global software development, change, configuration and \\ release management platform. \\ $\underline{\text { Selection of Course Topics (continued) }}$
}

Rational Logiscope Reviewer - automatic checking tool for industry's coding

standards, and locate complex, error-prone or duplicated code

Rational Software Architect and BIRT - UML, reporting

Rational Modeling Platform

Rational Application Developer (J2EE, Beans, JSF, Ajax, HTML)

Rational Application Developer for System z (COBOL, CICS, DB2)

UML, UML2, Model System Development Concepts, SysML, Object-Oriented

System Analysis and Design, Agile Development

Rational AppScan - Web Application Testing.

Rational Clear Case - Source Change Management

Rational Quality Manager, Manual and Functional Testing - Software Testing

Open Source

https://www14.software.ibm.com/web app/devtool/scholar/web/coursewareP ickPage.do?source=ai-course-

opensource

\section{WebSphere}

littps://www14.software.ibm.cotn/web app/devtool/scholar/web/coursewareP ickPage.do?source=ai-course-

websphere
Java Fundamentals using Eclipse, XML, Open Source Standards

J2EE and the WebSphere Application Server

WebSphere Application Server Administration

WebSphere Business Modeler and Business Monitor - simulate the effects of a

business model before and after deployment

WebSphere ILOG JRules - Business Rule Management

WebSphere eMash -RESTful Application Development

A selection of courseware topics applicable to the IS/CS curriculum includes UML, J2EE (WebSphere), COBOL II, CICS, DB2, IMS, Business Processing Modeling, Project Management (Rational), Information Infrastructure and Management, XML, software development concepts, application testing, database design, data warehousing (Cognos), data mining (SPSS), security, networking and business continuity. While some courseware topics are not vendor-specific, the majority of the courseware was designed to support a specific IBM technology or tool. The content, currency and quality of the IBM courseware varied. While the majority of the courseware content was excellent, some System z courseware needed to be upgraded. Videos, audio and web-delivered materials were lacking in many topic areas. 


\section{Issues in Information Systems}

Volume 13, Issue 2, pp. 182-192, 2012

The depth and scope of IBM Academic Initiative education materials is impressive. These educational resources and software will be valuable to most IS/CS faculty members and students. IBM provides an ACM guide to cross reference IBM products and courseware to specific computer science and information systems courses. Some courseware may be complete enough to support a specific course, while other courseware may not directly map to the customized objectives of other courses. This guide does not include references to other IBM Academic Initiative courseware materials. Faculty members should review all courseware related to a topic, including a review of other IBM Academic Initiative student and training resources. It is also recommend that instructors also review non-IBM videos and internet links to supplement their customized course design.

The design of IBM Academic Initiative web site reflects the organizational structure of IBM. BM product divisions are autonomous units. As a result, there was little standardization between or within major product line courseware sections of the IBM Academic Initiative Web Site. There were no cross-references between product line resources to other related academic topics. The Academic Initiative web site was difficult to use, and was organized by product line rather than IS/CS curriculum objectives. For example, IBM's Rational product line provides various tools to support project management, application development, collaboration and application testing. Unless a faculty member understood the details of each Rational tool, they may not appreciate the specific function of a Rational tool or relationship to other Rational tools to effectively develop IS/CS courses.

\section{Master the Mainframe Contest}

Each year IBM sponsors the IBM Master the Mainframe (System z) Contest. This contest is an out-reach strategy designed to expose high school students, university students and other professionals to IBM System z. The contest requires no prior computer knowledge. Participants have access to a remote virtual mainframe, online tutorials, technical support materials, and technical support. Hands-on skills are emphasized.

The contest is organized into three sections. The first two sections may be easily completed by anyone who reviews the tutorials and performs the hands-on requirements. The first two sections include many basic hardware and operating system topics normally covered in IS/CS core courses. Part 3 is considerably more challenging. Part 3 requires completion of an enterprise project. Participants may chose from several different application programming languages, including Java, C/C++ and COBOL. Entry-level knowledge of zEnterprise clients, z/OS or Linux operating systems, and SQL are provided in the contest tutorials and other sources. Technical support and feedback provided by the IBM staff to the contest participants was outstanding.

Contest requirements are changed and updated every year. Participants may register once per year. The contest submissions are graded by a member of the Master the Mainframe staff. When a student registers for the contest, they have the option to select an academic institution. A faculty member may request access to the contest scores for their class members. While Master the Mainframe Contest would be an excellent addition to any IS/CS Curriculum, it is only available during the months of October, November and December. The IBM Academic Initiative is investigating an approach to make the Master the Mainframe online courses material available to universities throughout the year.

Master the Mainframe participants have the opportunity to win debit cards, t-shirts, and other prizes. Winners of the contest are published in the Master the Mainframe Wall of Fame [23] and Facebook [24]. A review of participating institutions and participants indicate that the majority were either resided outside the United States or are located at high schools or universities near a major IBM facility. Using the Master the Mainframe contest to reach high school students may be an innovative high school recruiting tool. The IBM Summer Innovation Camp Dallas provides high school student hands-on experience with virtualization, mobile application development, Linux, and DB2 [25].

\section{SystemZ Mastery and Certification Exams}

Academic Initiative instructors may request a free SystemZ mastery test vouchers for their students and instructor. The content of the SystemZ Mastery exam is based text book "Introduction to the New Mainframe: z/OS Basics" 


\section{Issues in Information Systems}

Volume 13, Issue 2, pp. 182-192, 2012

[4]. This text book may be downloaded in PDF format or purchased as a text book. Discounted vouchers are available for retakes. Discounted vouchers (up to 50\%) are also available for other zEnterprise Certification Exams [29].

\section{RMU IBM Academic Advisory Board}

IBM is sensitive to the needs of their customers. In response to IBM customer concerns of the future availability of qualified IBM Enterprise System professionals, the Computer Information System (CIS) department of Robert Morris University (RMU) was approached by a representative of the IBM Academic Initiative in Fall, 2011. A second meeting between members of the CIS department and several Pittsburgh-area IBM Enterprise employers was convened in February, 2012.

Some RMU faculty had either professional or academic experience in IBM mainframes or COBOL. The Advisory Board consisted of several representatives from IBM, several Fortune 500-level IBM zEnterprise employers, and representatives from other IBM-related employers. Detailed undergraduate and graduate syllabuses for five zEnterprise courses were reviewed and approved by members of the RMU IBM Academic Advisory Board, the RMU Faculty and Administration. New zEnterprise course descriptions included Introduction to COBOL, Advanced COBOL, Enterprise Transaction Processing Systems using CICS/COBOL, Enterprise Operating Systems (z/OS), and Enterprise Database Systems (DB2).

While some of these courses may be available to IBM customers and employers through technical training courses, university courses offer several unique advantages. Training budgets are frequently cut during down business cycles. Education employee benefits are rarely reduced. Training classes rarely assess performance without a certification examination. Students will be assessed and graded by a qualified university professor. Finally, while training classes may earn continuing education credits, they do not earn university credits that may be applied to an undergraduate or graduate degree. Two 18-credit certificate programs were also created. The advantages of certificate program include emphasis on job skills, minimum admission requirements, and the ability to transfer credit to other academic degree programs.

The expertise provided by the RMU IBM Academic Advisory Board provided many benefits. These benefits included information dissemination, professional advisement, technical support, and a source of adjunct faculty. Two zEnterprise courses are scheduled to start in Fall of 2012. At the time of this writing both course sections were closed due to high enrollment.

\section{Level 1, Level 2 and Level 3 IBM Academic Initiative Support}

Hands-on access to a zEnterpise system is critical for the success of the IBM Academic Initiative. The IBM Academic Initiative provides three levels of support. Level 1 academic institutions are provided a zEnterprise infrastructure and virtual mainframe hosted at Marist College at no expense to the IBM Academic Initiative Partner. Technical support, course support, account management and other services are provided to the individual faculty member by the qualified staff at Marist College and IBM. Students are provided course support through the faculty member. Level 1 support is recommended for those institutions with limited experience in zEnterprise technologies. Level 1 support does provide faculty with the opportunity for personal zEnterprise research and course development.

Based on RMU's previous experience with IBM technologies, Robert Morris University started with Level 2 support. A virtual zEnterprise system was provided by the IBM Academic Initiative at no cost. Physically located in Dallas, TX, the IBM Academic Initiative technical staff provided operational support and faculty training. The primary objectives of Level 2 support are to engage and train IS/CS faculty to eventually take over the day-to-day management of the system and to provide the flexibility to introduce other zEnterprise products into the IS curriculum. 


\section{Issues in Information Systems}

Volume 13, Issue 2, pp. 182-192, 2012

Level 3 support provides a physical IBM Mainframe and Infrastructure hosted at the site of the IBM Academic Initiative institution. While an IBM zZEnterprise mainframe and infrastructure is provided at no cost for an Academic Initiative curriculum, few institutions have the necessary technical expertise to support and maintain a Level 3 physical mainframe. While prestigious, Level 3 support requires considerably more technical and physical resources of the hosted institutions.

Remote access to z/OS operating system, application languages, databases, and other resources may be provided by many clients. Popular z/Enterprise clients include PCOMM, Rational Application Developer for the zEnterprise (RDz), Putty, SSH tools, telnet, and FTP. Many of these tools can support a variety of local file systems, the z/OS file system, and zEnterprise Linux file system.

\section{Conferences, On-site and Virtual Training}

Each summer year Marist College, located in Poughkeepsei NY, hosts the "Enterprise Computing Community Conference" (ECC). ECC is two-day conference that provides a vehicle for faculty, researchers and IBM employers to share professional development seminars and ideas. Following the ECC conference IBM presents a three-day IBM Academic Initiative training program. Training seminars are presented by IBM's technical support staff, key IBM employers and experienced Academic Initiative faculty members. The three-day program also includes impressive tours of IBM mainframe testing and assembly centers. These tours may be scheduled for student groups during the normal semester. While conference expenses are free, the attendee must pay for travel, food and lodging.

SHARE and Innovate are two professional conferences that may be of interest to IBM Academic Initiative faculty. SHARE is an independent, zEnterprise-focused organization. SHARE volunteer members provide two semi-annual zEnterprise conferences, continuous enterprise technology webinars, education resources, training, professional networking and effective industry input [28]. SHARE conferences also provide third-party, zEnterprise access to IBM customers, professionals and members of the IBM Academic Initiative. Many third-party zEnterprise vendors also offer free software and training to IBM Academic Initiative institutions. The IBM Innovate Conference is a separate annual event designed to support IBM's Rational software product lines and other third-party vendors.

The IBM Academic Initiative makes every effort to train IBM Academic Initiative faculty. These efforts go beyond the education content of the IBM Academic Initiative web site. One-on-one and group virtual training may be customized to the unique needs of the faculty and curriculum. Academic Initiative members are encouraged to travel to Dallas [31] for personalized face-to-face training or group training sessions may be scheduled at the university location. Members of university advisory board may also offer training services.

\section{Engaging IBM Customers (Employers): Internships and Entry-level Careers}

The IBM Academic Initiative makes every effort to connect IBM customers, i.e., future employers, to the university and their students. Availability of student internships and entry-level careers through contacts provided by IBM Academic Initiative and our RMU IBM Advisory Board has increased. RMU is located in the Pittsburgh- area. Interviews with other IBM Academic Initiative institutions report that they are also impressed by the efforts to engage IBM customers and future employers. The IBM Academic Initiative also supports a Systemz Job Board, which is at no cost IBM customers and jobseekers [27]. It is important also to re-emphasize that zEnterprise provides careers beyond zEnterprise legacy application systems. zEnterprise employers also hire Java application programmers, virtualization, cloud computing, security specialists, and web application developers.

\section{CONCLUDING COMMENTS}

IBM academic partnerships offer IS/CS departmental opportunities to integrate legacy based technology with current object and new language technologies cost effectively and expediently. Facilitated by the prospect of internships and jobs for students and graduates support the outcomes focus and mandate of ABET-CAC accredited 


\section{Issues in Information Systems}

Volume 13, Issue 2, pp. 182-192, 2012

IS programs. The IBM Enterprise Systems integration opportunity provides academics with the infrastructure to both enhance curricular focus and knowledge to meet the needs of the future as they evolve.

Interviews with IS/CS faculty report their resistance to include vendor-specific technologies in the curriculum. Yet, the same faculty have no problems offering courses titled and based on Microsoft Office, VB.NET, C\#.NET, ASP.NET, and various Microsoft desktop and server operating systems. While Microsoft does provide free academic software through DreamSpark, Microsoft does not provide free access to free hardware or their moneymaking software, e.g., Microsoft Office, BI tools, etc.

Other faculty prefer open source software. IBM zEnterprise has supported open source software, both directly and financially. Open Office, Eclipse, BIRT, and Cassandra are examples of open source projects sponsored by IBM [30]. Open source software may be free, but technical support and faculty training comes at a cost. However, the IBM Academic Initiative provides quality open source courseware, technical support and faculty training at no cost.

IBM was the first to create virtualized operating systems (VM), multicore processors, controller-based I/O, cluster and cloud architectures (Sysplex and Parallel Sysplex), Time Sharing (TSO), OLTP (CICS), secure kernels, scripting JCL, CLIST and ReXX), the relational database (DB2), and SQL. Many of these topics are included in every IS/CS curriculum. If IBM was the first and dominates these technologies, one must consider how these topics should be included in IS/CS curriculum. Should IBM be ignored in the IS/CS curriculum, while Microsoft, Intel, or Unix gets the credit?

IBM zEnterprise is not as glamorous as an Android mobile application. Most IS/CS majors, high school students, and parents are unaware of zEnterprise systems and applications. There is no question that before the introduction of the IBM Academic Initiative in 2005 IBM had not adequately supported or listened to the needs IS/CS academic educators. From IBM's point of view, universities were simply another customer. Before 2005, IBM and their customers had no trouble in attracting and hiring the best qualified IS/CS graduates.

It is now well into the 21 st century, and times have changed. IBM has recognized and corrected their previous shortcomings. IBM's support and commitment for the Academic Initiative should be recognized by all IS/CS faculty. There is much work to do. IBM gets the best entry-level job candidates, IS/CS programs do not. Today IS/CS students have different learning styles and technology backgrounds than students a decade ago. It is also important to increase awareness of high school students, parents and other current majors of zEnterprise careers. The Master the Mainframe and summer camps are a good start.

The demand of zEnterprise internships, entry-level and professional career opportunities will continue to grow. High demand and low supply means higher entry-level salaries. zEnterprise employers search for vendor-specific keywords. IBM dominates world-wide transactional processing and is the foundation for many concepts in IS/CS education. Why shouldn't employers search for IBM zEnterprise keywords? IBM has learned and responded. It is time fort IS/CS faculty to learn that "vendor" is not a four-letter word. IS/CS curriculum faculty should not ignore significant vendor-specific career and salary opportunities for their students. It is time for zEnterprise and the IBM Academic Initiative to be included in the IS/CS curriculum.

\section{REFERENCES}

1. "Mainframe computer LPAR". (n.d.). Retrieved on 3/25/2012 from: http://en.wikipedia.org/wiki/Mainframe computer

2. Laverty, J. (2011). "Review of Program Languages offered By ABET CCAC-Accredited Institutions". Unpublished.

3. Enterprise Computing Community Conference. (2012). Retrieved on 3/25/2012 from: http://ecc.marist.edu/conf2Ol2/

4. Ebbers, M., Kettner, J., O'Brien, W, and Ogden. (2011). "Introduction to the New Mainframe: z/OS Basics". Third edition. Red Books. http://ibm.,com/redbooks

5. "z/VM". (n.d.). Retrieved on 3/15/2012 from: h ttp://www.vm.ibm.com/

6. "Definition of LPAR". (n.d.). Retrieved on 3/15/2012

from:http://www.pcmag.com/encyclopedia^term/0,2542,t=LPAR\&i=46363,00.asp 


\section{Issues in Information Systems}

Volume 13, Issue 2, pp. 182-192, 2012

7. "LPAR Configuration and Management". (2012). Retrieved on 3/15/2012 from: http://www.redbooks.ibm.com/redbooks/pdfs/sg24625.pdf

8. Milberg, K. (2009)." IBM and HP virtualization: A comparative study of UNIX virtualization on both platforms". Retrieved on 3/15/2012 from: http://www.ibm.com/developerworks/aix/library/au-aixhpvirtualization/index.html

9. "Logical partition (virtual computing platform)". (n.d.). Retrieved on 4/3/2012 from: http://en.wikipedia.org/wiki/Logical_partition (virtual_computing_platform)

10. "LPAR For Decision Makers". (2002). Retrieved on 3/15/2012 from: http://www.orizon-sys.com/Orizon-

Sys\%20Does/IBM\%20eServer\%\%20pSeries/LPAR\%20-\%20DLPAR/LPAR\%20OFor\%2ODecision\%20Makers.pdf 11. "Rational

Developer for System Z LPAR". (n.d.). Retrieved on 4/3/2012 from: http://www-01.ibm. com/software/rational/products/developer/systemz/

12. "Report: IBM Named Market Share Leader in Middleware Software". (2012). Retrieved on 4/3/2012 from: http://www-03. ibm. com/press/us/en/pressrelease/37376.wss

13. "IBM tighten stranglehold over Mainframe Market:Gets Hit with Antitrust Suite in Europe". (2008). Retrieved on 4/3/2012 from: http://openmainframe.org/news/ibm-tightens-stranglehold-over-mainframe-market-gets-hit-wit.html

14. "Get the facts". (n.d.). Retrieved on 4/3/2012 from:

http://www-03.ibm.com/systems/migratetoibm/getthefacts/mainframe.html\#4

15. Dignan, L. (2011). "IBM reclaims server market share revenue crown in Q4, says Gartner". Retrieved on 4/3/2012 from:

http://www.zdnet.com/blog/btl/ibm-reclaims-server-market-share-revenue-crown-in-g4-saysgartner/45334

16. Dignan, L. (2011). "Server sales surge: IBM share jumps; HP top dog; Oracle's Sun perks up". Retrieved on 4/3/2012 from: http://www.zdnet.com/blog/btl/server-sales-surge-ibm-share-jumps-hp-top-dog-oracles-sun-perks-

up/49284? tag=rbxccnbzd 1

17. "System z: Academic Initiative program". (n.d.). Retrieved on 4/1/2012 from:

http://www. ibm.com/university/systemz/

18. "Exploiting virtual machine technology for the development and test of z/OS system solutions". (n.d.). Retrieved on 4/9/2012

from: http://www.vm.ibm.com/zos/

19. "PNC Virtual Mobile Wallet". (n.d.). Retrieved on 4/4/11 from:

https://www.pncvirtualwallet.com/virtual wallet mobile.html.

20. "Academic Initiative membership". (n.d.). Retrieved on 4/4/11 from:

https://www.ibm.com/developerworks/university/membership/index.html

21. "Academic Initiative Courseware". (n.d.). Retrieved on 4/4/11 from:

https://www.ibm.com/developerworks/university/courseware/

22. "IBM Master the Mainframe Contest". (n.d.). Retrieved on 3/23/2012 from:

http://www. ibm.com/developerworks/university/students/contests/mainframe/

23. "Master the Mainframe Wall of Fame. (n.d.). Retrieved on 3/30/2012 from: http://www. ibm.

com/developerworks/university/students/contests/mainframe/winners.html 24. "Master the Mainframe Contest Face Book". (n.d.).

Retrieved on 3/30/2012 from: http://www.facebook.com/MasterTheMainframe

25. "IBM Summer Innovation Camp Dallas Courseware". (n.d.).. Retrieved on 6/11/2012 from:

https://wwwl4.software.ibm.com/webapp/dswdown/dswdown.wss/web/searchDescription

26. USA Today. (2012). "Top secret Visa data center banks on security, even has moat." Retrieved on 3/29/2012 from:

http://www.usatoday.com/tech/news/story/2012-03-25/visa-data-center/53774904/1

27. "SysteraZ Job Board ". (n.d.), Retrieved on 3/29/2012 from: http:/www.SystemzJobs.com

28. "Share". (n.d.), Retrieved on 3/29/2012 from: http://www.share.org/p/cm/ld/fid=4

29. "Training \& certification". (n.d.). Retrieved on 3/29/2012 from:

https://www.ibm.com/developerworks/university/training/certification.litml

30."Open source". (n.d.). Retrieved on 3/29/2012 from: https://www.ibm.coin/developerworks/opensource/

31. "System z event and training schedule". (n. d.). Retrieved on 3/29/2012 from:

http://www.ibm.com/developerworks/university/systemz/events.html 